\title{
DESEMPENHO AGRONÔMICO E RECOMENDAÇÕES PARA CULTIVO DE QUINOA (BRS SYETETUBA) NO CERRADO ${ }^{1}$
}

\author{
Carlos Roberto Spehar ${ }^{2}$, Juliana Evangelista da Silva Rocha ${ }^{2}$, Roberto Lorena de Barros Santos ${ }^{3}$
}

\section{ABSTRACT \\ AGRONOMIC PERFORMANCE AND RECOMMENDATIONS FOR QUINOA (BRS SYETETUBA) CROP IN THE BRAZILIAN SAVANNAH}

Quinoa (Chenopodium quinoa Willd.), native to the South American Andes, has been adapted for cultivation in Brazil, via progeny selection. Originating from the Q4 population, from Ecuadorian valleys, Q4.5 has shown outstanding performance. During the trials, it was standardized for agronomic traits and named BRS Syetetuba. In the summer and winter, it reached $2.3 \mathrm{tha}^{-1}$ and $7.5 \mathrm{tha}^{-1}$, respectively for grain and biomass yield, in 120 days, from emergence to maturity. These results were higher than those reached by the BRS Piabiru and Kancolla check cultivars. The grains are saponin-free and have a mean weight of

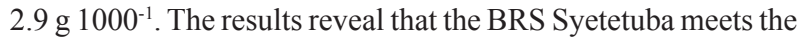
desirable characteristics for commercial yield in Brazil.

KEY-WORDS: Chenopodium quinoa; grain weight; biomass; plant height.

A Quinoa (Chenopodium quinoa Willd.), pertencente à família Amaranthaceae, subfamília Chenopodioideae, é originária dos Andes, onde tem sido cultivada há milênios (Mujica-Sanchez et al. 2001). Com grande variabilidade genética e relativa tolerância a estresses abióticos, como baixas temperaturas, déficit hídrico, salinidade e acidez (Jacobsen et al. 2003), a espécie desponta como opção para diversificar a agricultura brasileira. Nos últimos anos, parcerias entre a Embrapa Cerrados, Universidade de Brasília e agricultores têm estimulado a sua adaptação e cultivo no Brasil (Spehar 2007).

Seu grão possui proteína de qualidade, que atende às necessidades básicas em aminoácidos essenciais, no balanceamento protéico de alimentos e ração animal. Ademais, atende, também, à crescente demanda por alimentos equilibrados e funcionais,

\section{RESUMO}

A Quinoa (Chenopodium quinoa Willd.), originária dos Andes, tem sido adaptada ao cultivo no Brasil, via seleção de progênies. Entre as progênies avaliadas, tem-se destacado a Q4.5, proveniente da população Q4, originária dos vales equatorianos. O genótipo foi uniformizado em suas características agronômicas, recebendo o nome de BRS Syetetuba. Em experimentos de verão e entressafra, apresentou rendimentos de 2,3 $\mathrm{t} \mathrm{ha}^{-1}$ de grãos e 7,5 $\mathrm{t} \mathrm{ha}^{-1}$ de biomassa total, em 120 dias, da emergência à maturação. Estes resultados superaram aqueles alcançados pelas cultivares padrões BRS Piabiru e Kancolla. Os grãos são livres de saponina e têm peso médio de $2,9 \mathrm{~g} 1000^{-1}$. Os resultados indicam que a BRS Syetetuba reúne características favoráveis para desencadear a produção comercial de quinoa no Brasil.

PALAVRAS-CHAVE: Chenopodium quinoa; peso de grãos; biomassa; altura de planta.

relacionada à busca de alternativas dietéticas, como a ausência de glúten. Com estas propriedades, a quinoa tem sido demandada mundialmente, o que tem levado à expansão de seu cultivo, inclusive como alternativa aos cultivos comerciais.

No Brasil, desde a década de 1990, tem-se confirmado o potencial de cultivo comercial desta espécie, na região do Cerrado (Spehar \& Souza 1993, Spehar 2007). Como consequência, a produção brasileira poderá suplementar um mercado externo crescente, que exige características específicas como grãos grandes (maiores que 3,0 g 1000-1), ausência de saponina (detergente natural de sabor amargo formado por glicosídeos) e boa qualidade nutricional. Grãos desprovidos de saponina permitem seu uso direto na alimentação, sem a remoção do envoltório do fruto (aquênio), que contém tal substância.

1. Trabalho recebido em mar./2010 e aceito para publicação em jan./2011 (nº registro: PAT 9395/ DOI 10.5216/pat.v41i1.9395).

2. Universidade de Brasília, Campus Universitário Darcy Ribeiro, Faculdade de Agronomia e Medicina Veterinária, Brasília, DF, Brasil.E-mails: spehar@unb.br, julianaesr@hotmail.com.

3. Ministério da Agricultura, Secretaria Executiva, Brasília, DF, Brasil.E-mail: roberto.lorena@agricultura.gov.br. 
Tais características têm sido alvo de programas de melhoramento da quinoa, inclusive no Brasil (Spehar 2007). No Cerrado, em latitudes aproximadas de $15^{\circ} \mathrm{S}$ e altitudes entre $800 \mathrm{~m}$ e $1.100 \mathrm{~m}$, o ciclo precoce também é desejável, haja vista a maior facilidade de manejo da lavoura e a melhoria da qualidade do produto colhido (grãos), do rendimento e da eficiência relativa (Spehar \& Santos 2005). Demonstra-se que, nem sempre, a elevada produção de biomassa, associada ao ciclo mais tardio, influenciando o crescimento das plantas, é acompanhada de maior rendimento e qualidade de grãos (Spehar \& Santos 2002).

A linhagem BRS Syetetuba (em tupi-guarani, Syetetuba significa sementes boas e abundantes), objeto desta comunicação, foi obtida por seleção individual (plantas trilhadas separadamente), seguida de avaliação de progênies, a partir da população Q4, originária dos vales andinos do Equador, situados em altitude média de $2.500 \mathrm{~m}$. Desta população, que apresentava plantas com variações morfológicas em semeaduras no Cerrado, foi selecionada a progênie Q4.5, que apresentou características desejáveis como ausência de saponina, grãos grandes e relativa homogeneidade fenotípica. Como já enfatizado, tais características são o alvo principal da seleção, além de outras relacionadas a número de dias para a maturação, arquitetura da planta e rendimento de grãos.

A linhagem Q4.5 destacou-se em ensaios conduzidos por duas safras (2006 e 2007), em Planaltina, DF (dois ensaios), e Cristalina, GO, em competição com as cultivares testemunhas BRS Piabiru e Kancolla. A primeira destas é a cultivar pioneira de quinoa recomendada para o Brasil e a segunda é originária do altiplano boliviano-peruano. Os locais de experimentação, com latitudes entre $15^{\circ} \mathrm{S}$ e $16^{\circ} \mathrm{S}$, apresentam Latossolo Vermelho Escuro e Latossolo Amarelo, em Planaltina, e Latossolo Amarelo, em
Cristalina. Em todos eles, os solos foram previamente corrigidos (Spehar \& Rocha 2010).

BRS Syetetuba possui hipocótilo de coloração rosa claro e suas folhas, com polimorfismo, apresentam deposição de oxalato de cálcio, típica da espécie. O caule, ereto, é verde ou verde estriado, ocorrendo plantas com caule roxo e, algumas delas, são ramificadas. A inflorescência, diferenciada e terminal, amarantiforme e laxa, caracteriza-se por apresentar coloração amarela, quando a planta atinge a maturação fisiológica. Os grãos (frutos), cilíndricos e achatados, apresentam pericarpo branco, sendo envolvidos pelo perigônio, que se abre na maturação. Variações fenotípicas associam-se a cruzamentos naturais de frequência variável, podendo atingir até $30 \%$, nas condições do planalto central brasileiro.

Suas plantas, resistentes ao acamamento, apresentam estatura mediana de $1,8 \mathrm{~m}$, da qual a inflorescência representa 0,6-0,7 m. A diferenciação floral ocorre aos 30 dias após a emergência e a antese inicia-se aos 45 dias. O período entre a emergência e a maturação fisiológica é de cerca de 120 dias. Os grãos prontos para o armazenamento, com umidade

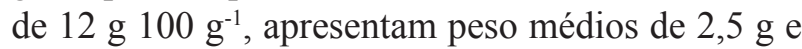
3,3 g por mil grãos, nos cultivos respectivos de verão

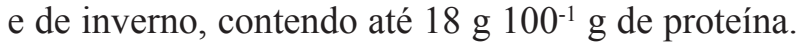
Os dados de rendimento, em relação às cultivares padrão BRS Piabiru e Kancolla, são apresentados na Tabela 1.

Os valores médios de rendimento no período foram de 2,3 tha ${ }^{-1}$ de grãos, com 7,5 tha ${ }^{-1}$ de biomassa total e índice de colheita (IC) médio de 0,31 (dados não apresentados). Este índice, que é uma medida da eficiência produtiva da planta (expressa a proporção de grãos na biomassa total), pode ser considerado alto, pois foi equivalente ao da cultivar Kancolla e superior ao da Piabiru. Em síntese, o rendimento elevado, em ciclo de 120 dias, evidencia a viabilidade econômica

Tabela 1. Rendimento de grãos $\left(\mathrm{t} \mathrm{ha}^{-1}\right)$ de quinoa, genótipo BRS Syetetuba, em relação às cultivares padrão BRS Piabiru e Kancolla, no período 2006-2007, em três locais ${ }^{1}$.

\begin{tabular}{|c|c|c|c|c|}
\hline \multirow{2}{*}{ Ano } & \multirow{2}{*}{ Local } & \multirow{2}{*}{$\begin{array}{c}\text { BRS } \\
\text { Syetetuba }\end{array}$} & \multicolumn{2}{|c|}{ Testemunha } \\
\hline & & & BRS Piabiru & Kancolla \\
\hline 2006 & Embrapa, Planaltina, DF & 2,0 & 1,2 & 1,4 \\
\hline \multirow{4}{*}{$2006-2007$} & Fazenda Moça Terra, Planaltina, DF (1) & 2,6 & 2,4 & 0,9 \\
\hline & Fazenda Moça Terra, Planaltina, DF (2) & 2,4 & 1,8 & 1,6 \\
\hline & Fazenda Dom Bosco, Cristalina, GO & 2,3 & 1,8 & 2,1 \\
\hline & Média Geral & 2,3 & 1,8 & 1,5 \\
\hline
\end{tabular}

${ }^{1}$ Valores obtidos em cultivo de sucessão e entressafra, sob precipitação de $450 \mathrm{~mm}$. 
do cultivo deste material no Brasil (Spehar \& Rocha 2010).

Além das características fenológicas e de rendimento, realizou-se, ainda, nos ensaios, levantamento de micro-organismos e insetos associados à cultura. Doenças típicas da espécie, como o míldio (Peronospora farinosa), e pragas como a mariposa Eurysacca melanocampta não foram encontrados, confirmando-se a ausência de seu registro no Brasil (Spehar 2007). Houve incidência de percevejos de várias espécies, incluindo os que atacam a soja, como Nezara viridula, Pyezodorus guildinii e Euschistos heros, sem dano aparente aos grãos. Depois da colheita, verificou-se, ainda, a ocorrência de gorgulho do trigo (Sitophilus granarius) e de traças-dos-cereais (Ephestia kuehniella e Plodia interpunctela), insetos que, geralmente, atacam grãos de quinoa.

Entre as recomendações básicas para o cultivo, a semeadura se faz, preferencialmente, em sulcos, espaçados em 40-50 cm, evitando-se cobrir as sementes com mais de $2,0 \mathrm{~cm}$ de solo. A população final esperada é de 500 mil plantas $^{-1}$, embora haja indicação de não haver diferença no rendimento entre populações variando de 100 mil a 600 mil plantas ha $^{-1}$ (Spehar \& Rocha 2009). No florescimento, a lavoura, estando uniforme, cobre totalmente o solo, com populações próximas ao limite superior. A baixa competitividade, no início do crescimento, pode ser contornada semeando-se diretamente em sulcos, sobre os resíduos do cultivo anterior. Assim, quando surgem as plantas invasoras, a cultura encontra-se na fase de crescimento rápido, mais competitiva. Para o controle químico das plantas invasoras, podem ser utilizados os herbicidas alachlor, setoxydin e metamitrona.

O cultivo de BRS Syetetuba pode ser realizado em safrinha e entressafra. Para a produção de grãos com qualidade, é necessário o planejamento da semeadura, a qual deve ser realizada entre janeiro e junho, possibilitando colheita em plena seca. Para rendimento esperado de 2,0 $\mathrm{t} \mathrm{ha}^{-1}$, a adubação de manutenção, com base na composição da planta e assumindo-se o solo corrigido, é de $80-100 \mathrm{~kg} \mathrm{ha}^{-1}$, tanto de $\mathrm{P}_{2} \mathrm{O}_{5}$ como de $\mathrm{K}_{2} \mathrm{O}$. O nitrogênio deve ser parcelado: $20-30 \mathrm{~kg}$ na semeadura e $40-50 \mathrm{~kg} \mathrm{ha}^{-1} \mathrm{em}$ cobertura, aos 30-50 dias após a emergência.

A linhagem BRS Syetetuba amadurece como a soja ou o trigo, ou seja, a planta inteira entra em senescência e seca, facilitando a colheita. Por possuir sementes pequenas, comparativamente a outras espécies cultivadas, como a soja e o feijão, há necessidade de regulagem da colhedora, para reduzirem-se as perdas na operação de colheita (Spehar \& Santos 2005). Por fim, durante o armazenamento, deve-se realizar o expurgo dos grãos, para se evitar a proliferação de pragas associadas.

\section{REFERÊNCIAS}

JACOBSEN, E. S.; MUJICA, A.; JENSEN, C. R. The resistance of quinoa (Chenopodium quinoa Willd.) to adverse abiotic conditions. Food Reviews International, London, v. 19, n. 1/2, p. 99-109, 2003.

MUJICA-SANCHEZ, A. et al. Quinua (Chenopodium quinoa Willd.): ancestral cultivo andino, alimento del presente y del futuro. Santiago: FAO, 2001.

SPEHAR, C. R. Quinoa: alternativa para a diversificação agrícola e alimentar. Planaltina: Embrapa Cerrados, 2007.

SPEHAR, C. R.; ROCHA, J. E. S. Effect of sowing density on plant growth and development of quinoa, genotype 4.5, in the Brazilian savannah highlands. Bioscience Journal, Uberlândia, v. 25, n. 4, p. 53-58, 2009.

SPEHAR, C. R.; ROCHA, J. E. S. Exploiting genotypic variability from low-altitude Brazilian savannah-adapted Chenopodium quinoa. Euphytica, Dordrecht, v. 175, n. 1, p. 13-21, 2010.

SPEHAR, C. R.; SANTOS, R. L. B. Agronomic performance of quinoa selected in the Brazilian savannah. Pesquisa Agropecuária Brasileira, Brasília, DF, v. 40, n. 6, p. 609-612, 2005.

SPEHAR, C. R.; SANTOS, R. L. B. Quinoa (Chenopodium quinoa Willd) BRS Piabiru alternative for crop diversification. Pesquisa Agropecuária Brasileira, Brasília, DF, v. 37, n. 6, p. 889-893, 2002.

SPEHAR, C. R.; SOUZA, P. I. M. Adaptação da quinoa (Chenopodium quinoa Willd.) ao cultivo nos cerrados do planalto central: resultados preliminares. Pesquisa Agropecuária Brasileira, Brasília, DF, v. 28, n. 5, p. 635639, 1993. 